\title{
UK Renal Registry 19th Annual Report: Chapter 11 Centre Variation in Access to Kidney Transplantation (2010-2015)
}

\author{
Dominic Taylor $^{\text {ab }}$, Matthew Robb ${ }^{c}$, Anna Casula ${ }^{\mathrm{b}}$, Fergus Caskey ${ }^{\text {bde }}$ \\ a University of Southampton, Southampton, UK; ${ }^{b}$ UK Renal Registry, Bristol, UK; ${ }^{c}$ Organ Donation and Transplantation \\ Directorate, NHS Blood and Transplant, Bristol, UK; ${ }^{\mathrm{d}}$ North Bristol NHS Trust, Bristol, UK, e University of Bristol, Bristol, UK
}

\section{Keywords}

Centre variation - Comorbidity · Donor after brainstem death - Donor after cardiac death · Equity of access · Living kidney donor · Outcomes · Patient factors - Quality improvement · Renal transplantation · Transplant waiting list

\section{Summary}

- Patients of non-White ethnicity had, for the first time, an equal chance of being listed to receive a kidney transplant within two years of starting renal replacement therapy (OR 1.03, 95\% CI 0.931.15). This overall improvement in equity of access to transplantation belies a persisting reduced odds of receiving a transplant once on the waiting list.

- Patients treated at non-transplanting renal centres were less likely to be wait listed for transplantation compared to patients treated at transplanting renal centres (OR 0.78, 95\% CI 0.72-0.85).
- Patients treated at non-transplanting renal centres were less likely to receive a transplant from a donor after cardiac death or living kidney donor compared to patients treated at a transplanting renal centre (OR 0.79, 95\% CI 0.71-0.89).

- Once wait listed for transplantation, patients from both transplanting and non-transplanting renal centres had an equal chance of receiving a transplant from a donor after brainstem death (OR $1.03,95 \%$ CI $0.88-1.20$ ).

- After adjustment for case mix, there were significant differences between renal centres in the rate of transplant wait listing $(p<0.0001)$, time from start of renal replacement therapy to wait listing $(p<0.0001)$, rate of transplantation from a donor after brainstem death $(p=0.0046)$ and rate of transplantation from a donor after cardiac death or living donor $(p<0.0001)$.

\section{KARGER}

Fax +4161306 1234 E-Mail karger@karger.com www.karger.com/nef
This article is licensed under the Creative Commons AttributionNonCommercial-NoDerivatives 4.0 International License (CC BYNC-ND) (http://www.karger.com/Services/OpenAccessLicense). distribution of modified material requires written permission.
Dominic Taylor

UK Renal Registry, Southmead Hospital, Southmead Road,

Bristol, BS10 5NB, UK

Email: renalregistry@renalregistry.nhs.uk 


\section{Introduction}

Kidney transplantation is associated with improved clinical outcomes and quality of life compared to dialysis [1-3], so is the preferred method of renal replacement therapy (RRT) for clinically-suitable patients. Early transplantation minimises time on dialysis, a factor associated with reduced graft and patient survival. Further, early transplant wait listing increases the probability of transplantation from a deceased donor because the current national kidney allocation scheme [4] prioritises potential transplant recipients who have accrued more time on the waiting list. Therefore, renal centres achieving earlier transplant wait listing provide their patients with a clinical advantage.

This analysis aims to evaluate whether access to transplant wait listing and access to transplantation is equitable in the UK. Rates of wait listing and rates of transplantation after wait listing (i.e. conversion efficiency from wait listing to transplantation) were analysed according to patient characteristics. Time taken to wait listing was also analysed. Differences between renal centres and between transplanting versus non-transplanting renal centres were analysed, with adjustment for case mix.

\section{Methods}

\section{Study population}

To identify factors which influence the likelihood of wait listing for transplantation, an incident RRT cohort was analysed. All adult patients starting RRT between 1st January 2010 and 31st December 2012 at renal centres returning data to the UK Renal Registry ( $N=71$ centres) were considered for inclusion $(N=20,268$ patients). Patients aged 65 years and over $(10,026)$, patients listed for multi-organ transplants other than kidney and pancreas $(N=41)$ and patients who were suspended for more than 30 days within 90 days of wait listing $(N=464)$ were excluded. The latter exclusion avoided any potential bias from centres that may activate patients on the transplant list and then immediately suspend them before reactivation after medical assessment of a patient's fitness for transplantation. The remaining 9,737 patients were followed until two years from RRT start (latest 31st December 2014), until they were registered on the waiting list for a kidney transplant alone or kidney and pancreas transplant, or until death, whichever was earliest.

To identify factors which influence the likelihood of transplantation, patients from the above cohort who were wait listed before 31st December 2013 were identified. These 5,555 patients were followed until two years after wait listing (latest 31st December 2015), until they received a kidney transplant alone or kidney and pancreas transplant, or until death, whichever was earliest.
For patients transplanted after starting dialysis, renal centre is recorded by the UKRR as the centre providing dialysis. For patients transplanted pre-emptively, there may be instances where the renal centre recorded is the transplanting centre, even when work-up has taken place in a non-transplanting centre.

Data analysed

Baseline data

UK Renal Registry (UKRR) data included start date of RRT and patient characteristics including age group (18-29, 30-39, 40-49, $50-59$, or 60-64 years), gender, ethnicity (White, non-White, missing) and primary renal diagnosis (PRD, classified as: diabetes, other, missing). Date of wait listing and date of transplantation were provided by the UK Transplant Registry, held by the Organ Donation and Transplantation Directorate of NHS Blood and Transplant.

\section{Outcome variables}

Proportion of incident dialysis patients wait listed within two years of RRT start. In addition to patients wait listed during the study period, any patient who received a living donor transplant within two years of RRT start was also included, even if they were not on the national transplant waiting list before transplantation.

Days from RRT start to transplant wait listing. For all patients formally wait listed after starting dialysis, time from dialysis start to wait listing was used. Patients receiving a pre-emptive transplant (living or deceased-donor) were recorded as wait listed on the day of starting RRT (i.e. time to wait listing: zero days). Patients who received a living donor transplant after starting dialysis who had not been formally wait listed prior to transplantation were recorded as wait listed on the day of transplantation.

Conversion efficiency: the proportion of wait listed patients receiving a transplant within two years of listing. Transplants from donors after brainstem death were considered separately from transplants from donors after cardiac death or living donors, because of differences in the process of allocation. Kidneys from donors after brainstem death are allocated according to national allocation policy, while kidneys from donors after cardiac death are allocated regionally according to the 2006 donor after brainstem death kidney allocation scheme, and one kidney from each donor is offered to the local transplant centre [4]. The process of living donor transplantation is managed by the transplanting centre (and referring non-transplanting centre).

\section{Statistical methods}

Logistic regression models were fitted to examine the relationship between patient characteristics (age group, ethnicity, gender and PRD) and transplant wait listing within two years of RRT start, or receipt of a transplant within two years of wait listing. The proportion of all incident RRT patients listed for transplantation within two years of RRT start and the proportion of wait listed patients who were transplanted within two years were calculated for each renal centre, with adjustment for the above patient characteristics. Differences in outcome measures between transplanting and non-transplanting renal centres were assessed. The overall effect of renal centre on each outcome variable was measured by including renal centre as a random effect in a riskadjusted logistic regression model. The significance of any variation between centres was determined using a log likelihood 
ratio test that provided the change in the value of $-2 \log L$ on inclusion of the random centre effect.

Median time from RRT start to wait listing at each renal centre was estimated by Kaplan-Meier analysis, censored at death or on 31st December 2014, whichever was earlier. This methodology takes into account all patients at risk of wait listing during the study period, not only those who were wait listed. The effect of renal centre on time to wait listing was calculated by including renal centre as a covariate in a Cox regression model for time to wait listing amongst patients from all centres. Median times to wait listing by centre (and their confidence intervals) were derived by simulations based on the actual data.

Funnel plots are used to present the results for each outcome variable, providing a visual comparison of the relative performance of renal centres. Where appropriate, funnel plots are adjusted for patient characteristics known to influence each outcome, based on the results of the logistic regression models described above. The solid black line in each funnel plot indicates the national average. Dashed lines indicate $95 \%$ and $99.8 \%$ confidence intervals, which correspond to two and three standard deviations from the mean. Each point on the plot represents one renal centre. For each outcome measure, if no significant between-centre variation is present, three of 71 renal centres would be expected to fall between the $95 \%$ and $99.8 \%$ confidence intervals and no centre should fall outside the $99.8 \%$ confidence interval. Funnel plots showing the proportion of patients transplanted at two years after wait listing excluded those centres $(N=2)$ with fewer than 10 patients wait listed at the start of the study period.

SAS 9.3 was used for all analyses. A $P$ value below 5\% was considered statistically significant. The analysis described is based on the methodology described in chapter 11 of the UKRR 17th Annual Report [5] and a previous independently peerreviewed publication [6].

\section{Results}

Table 11.1 shows results from logistic regression analysis of the relationship between patient characteristics and the odds of transplant wait listing at two years from RRT start. There were missing ethnicity data for $7.8 \%$ of patients and missing PRD data for 3.7\%.

Tables 11.2 and 11.3 show results from logistic regression analyses of the relationship between patient characteristics and the likelihood of receiving a transplant from a donor after brainstem death or from a donor after cardiac death/living kidney donor within two years of wait listing, respectively. Ethnicity data were missing for $7.1 \%$ of patients and PRD for 3.3\%.

A patient starting dialysis in a non-transplanting renal centre was less likely to be wait listed for transplantation (OR 0.78, 95\% CI 0.72-0.85) or receive a transplant from a donor after cardiac death or living donor (OR 0.79, 95\% CI 0.71-0.89) compared with patients managed in transplanting renal centres. Once active on the transplant waiting list, patients in both transplanting and nontransplanting renal centres had an equal chance of receiving a transplant from a donor after brainstem death (OR 1.03, 95\% CI 0.88-1.20).

After adjusting for patient characteristics, there were significant differences between renal centres in the proportion of patients wait listed for transplantation at two years from RRT start (change in $-2 \log \mathrm{L}=164.6$,

Table 11.1. Logistic regression model showing the relationship between patient characteristics and odds of transplant wait listing within two years of RRT start

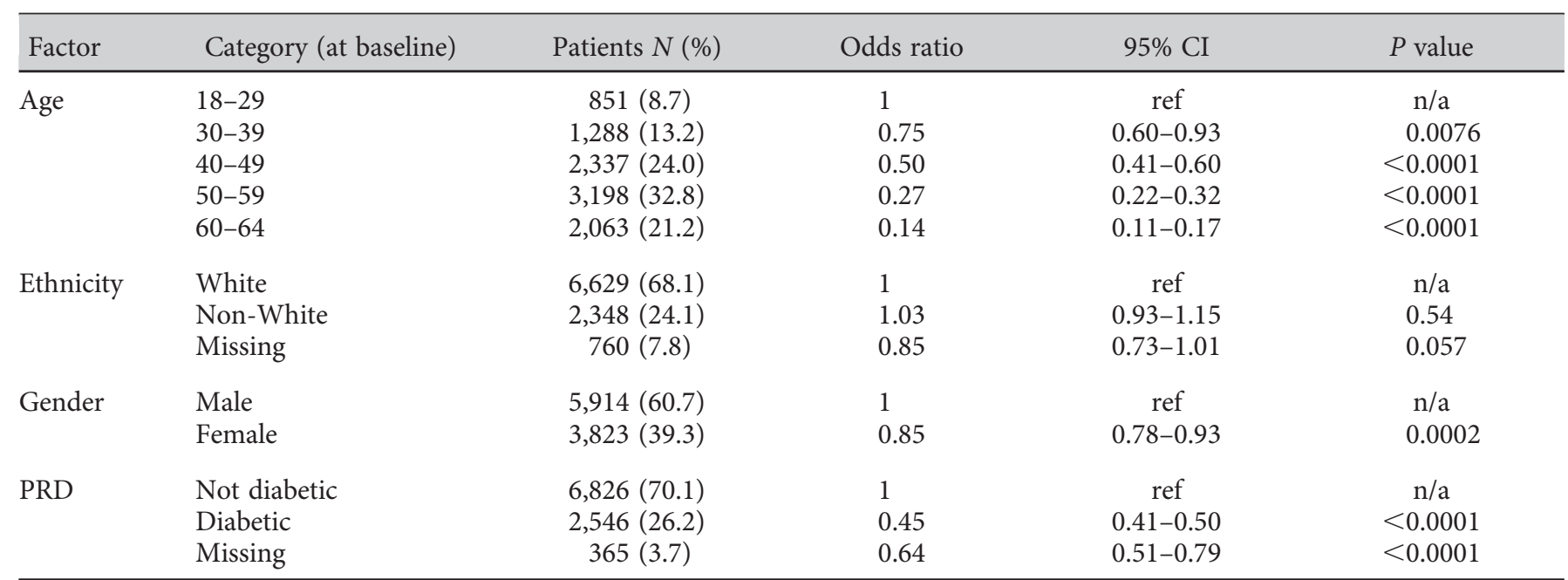

ref - reference category; n/a - not applicable 
Table 11.2. Logistic regression model showing the relationship between patient characteristics and odds of receiving a transplant from a donor after brainstem death within two years of wait listing

\begin{tabular}{|c|c|c|c|c|c|}
\hline Factor & Category (at baseline) & Patients $N(\%)$ & Odds ratio & $95 \% \mathrm{CI}$ & $P$ value \\
\hline Age & $\begin{array}{l}18-29 \\
30-39 \\
40-49 \\
50-59 \\
60-64\end{array}$ & $\begin{array}{r}702(12.6) \\
971(17.5) \\
1,535(27.6) \\
1,626(29.3) \\
721(13.0)\end{array}$ & $\begin{array}{l}1 \\
1.18 \\
0.89 \\
0.47 \\
0.35\end{array}$ & $\begin{array}{c}\text { ref } \\
0.91-1.53 \\
0.70-1.14 \\
0.36-0.61 \\
0.24-0.49\end{array}$ & $\begin{array}{c}\mathrm{n} / \mathrm{a} \\
0.20 \\
0.36 \\
<0.0001 \\
<0.0001\end{array}$ \\
\hline Ethnicity & $\begin{array}{l}\text { White } \\
\text { Non-White } \\
\text { Missing }\end{array}$ & $\begin{array}{c}3,770(67.9) \\
1,387(25.0) \\
398(7.1)\end{array}$ & $\begin{array}{l}1 \\
0.79 \\
1.29\end{array}$ & $\begin{array}{c}\text { ref } \\
0.65-0.95 \\
0.97-1.70\end{array}$ & $\begin{array}{l}\mathrm{n} / \mathrm{a} \\
0.0012 \\
0.078\end{array}$ \\
\hline Gender & $\begin{array}{l}\text { Male } \\
\text { Female }\end{array}$ & $\begin{array}{l}3,430(61.8) \\
2,125(38.2)\end{array}$ & $\begin{array}{l}1 \\
1.12\end{array}$ & $\begin{array}{c}\text { ref } \\
0.96-1.31\end{array}$ & $\begin{array}{c}\mathrm{n} / \mathrm{a} \\
0.17\end{array}$ \\
\hline PRD & $\begin{array}{l}\text { Not diabetic } \\
\text { Diabetic } \\
\text { Missing }\end{array}$ & $\begin{array}{c}4,341(78.1) \\
1,031(18.6) \\
183(3.3)\end{array}$ & $\begin{array}{l}1 \\
2.72 \\
1.18\end{array}$ & $\begin{array}{c}\text { ref } \\
2.28-3.24 \\
0.76-1.83\end{array}$ & $\begin{array}{c}\mathrm{n} / \mathrm{a} \\
<0.0001 \\
0.46\end{array}$ \\
\hline
\end{tabular}

ref - reference category; n/a - not applicable

Table 11.3. Logistic regression model showing the relationship between patient characteristics and the odds of receiving a transplant from a donor after cardiac death or living kidney donor within two years of wait listing

\begin{tabular}{|c|c|c|c|c|c|}
\hline Factor & Category (at baseline) & Patients N (\%) & Odds ratio & $95 \% \mathrm{CI}$ & $P$ value \\
\hline Age & $\begin{array}{l}18-29 \\
30-39 \\
40-49 \\
50-59 \\
60-64\end{array}$ & $\begin{array}{r}702(12.6) \\
971(17.5) \\
1,535(27.6) \\
1,626(29.3) \\
721(13.0)\end{array}$ & $\begin{array}{l}1 \\
0.64 \\
0.47 \\
0.46 \\
0.44\end{array}$ & $\begin{array}{c}\text { ref } \\
0.52-0.78 \\
0.39-0.56 \\
0.38-0.55 \\
0.36-0.55\end{array}$ & $\begin{aligned} & \mathrm{n} / \mathrm{a} \\
&< 0.0001 \\
&<0.0001 \\
&<0.0001 \\
&<0.0001\end{aligned}$ \\
\hline Ethnicity & $\begin{array}{l}\text { White } \\
\text { Non-White } \\
\text { Missing }\end{array}$ & $\begin{array}{c}3,770(67.9) \\
1,387(25.0) \\
398(7.1)\end{array}$ & $\begin{array}{l}1 \\
0.45 \\
0.62\end{array}$ & $\begin{array}{c}\text { ref } \\
0.39-0.51 \\
0.50-0.77\end{array}$ & $\begin{array}{c}\mathrm{n} / \mathrm{a} \\
<0.0001 \\
<0.0001\end{array}$ \\
\hline Gender & $\begin{array}{l}\text { Male } \\
\text { Female }\end{array}$ & $\begin{array}{l}3,430(61.8) \\
2,125(38.2)\end{array}$ & $\begin{array}{l}1 \\
0.87\end{array}$ & $\begin{array}{c}\text { ref } \\
0.78-0.98\end{array}$ & $\begin{array}{c}\mathrm{n} / \mathrm{a} \\
0.018\end{array}$ \\
\hline PRD & $\begin{array}{l}\text { Not diabetic } \\
\text { Diabetic } \\
\text { Missing }\end{array}$ & $\begin{array}{c}4,341(78.1) \\
1,031(18.6) \\
183(3.3)\end{array}$ & $\begin{array}{l}1 \\
0.54 \\
0.90\end{array}$ & $\begin{array}{c}\text { ref } \\
0.46-0.63 \\
0.66-1.22\end{array}$ & $\begin{array}{c}\mathrm{n} / \mathrm{a} \\
<0.0001 \\
0.50\end{array}$ \\
\hline
\end{tabular}

ref - reference category; n/a - not applicable

$\mathrm{df}($ degrees of freedom $)=1, p<0.0001$, see figure 11.1 and table 11.4).

After adjusting for patient characteristics, there were significant differences between renal centres in the proportion of patients receiving a renal transplant within two years of wait listing. This was true for transplants from donors after brainstem death (change in $-2 \log \mathrm{L}=8.1, \mathrm{df}=1, p=$ 0.0046 , see figure 11.2 and table 11.5) and transplants from donors after cardiac death or living donors (change in $-2 \log \mathrm{L}=162.6, \mathrm{df}=1, p<0.0001$, see figure 11.3 , table 11.5). Several centres fell outside the $95 \%$ and $99.8 \%$ confidence intervals.

Table 11.6 shows unadjusted median days from RRT start to transplant wait listing for each renal centre.

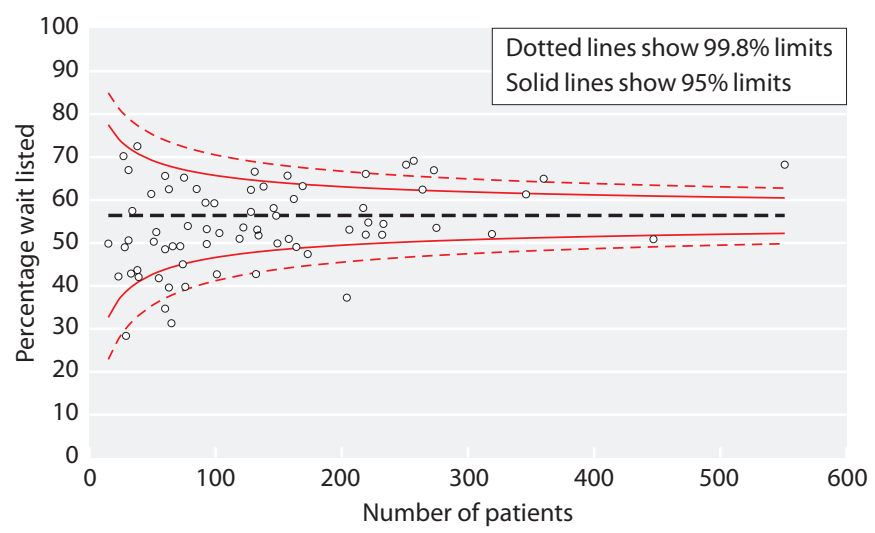

Fig. 11.1. Proportion of patients wait listed within 2 years of RRT start 
Table 11.4. Proportion of patients in each renal centre wait listed for a kidney transplant prior to or within two years of RRT start

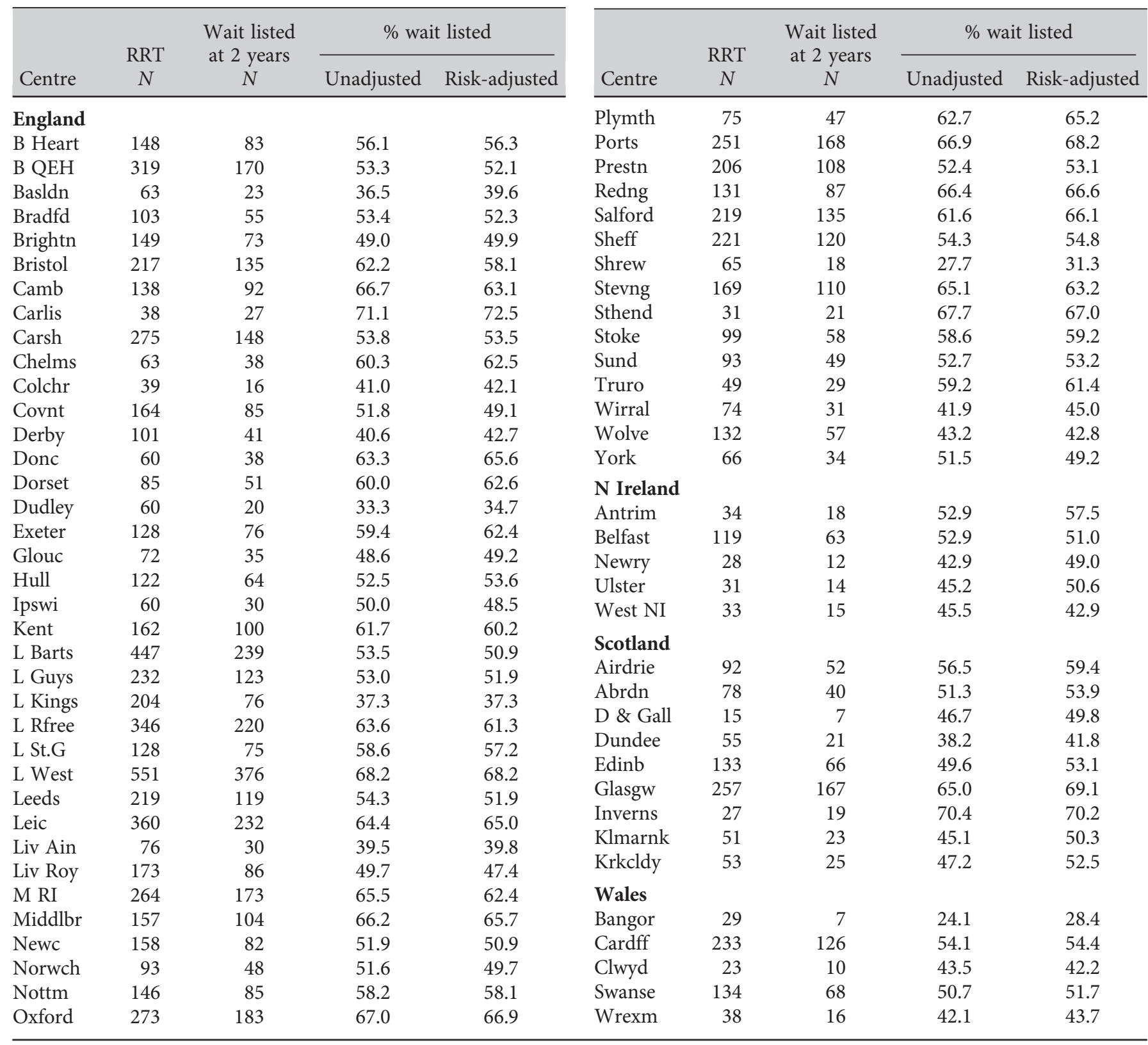

Figure 11.4 shows a funnel plot of adjusted median days from RRT start to transplant wait listing, with confidence intervals. These values were derived from simulations based on the actual data and for four centres (those with fewer events and/or longer waiting times), median values could not be estimated, so final event times are shown. The Cox model giving a risk-adjusted analysis of time to wait listing identified significant variation between renal centres (change in $-2 \log \mathrm{L}=313.2$, $\mathrm{df}=70, p<0.0001)$. In general, renal centres with the longest unadjusted waiting times also had the longest risk-adjusted waiting times. The centre lying outside the upper $99.8 \%$ confidence limit had a hazard ratio that indicated a significant delay in the chance of wait listing compared with a baseline centre that had a median time comparable to the national median. 


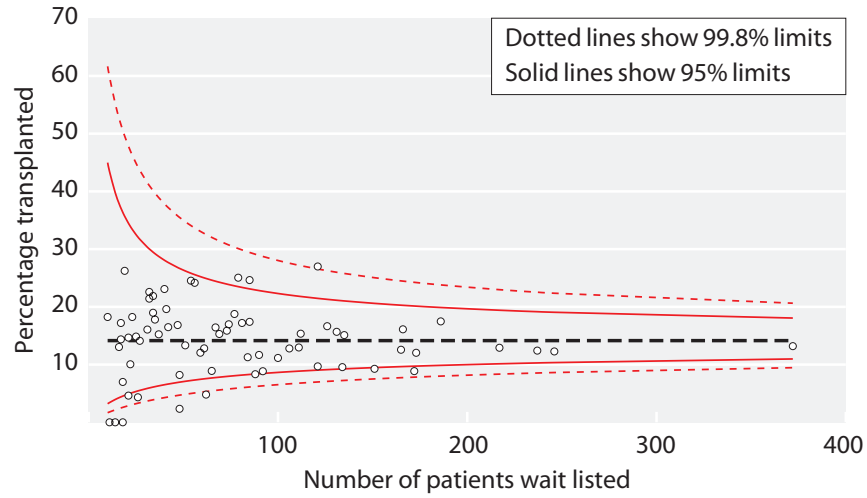

Fig. 11.2. Proportion of patients receiving a donor after brainstem death transplant within 2 yrs of wait listing (excluding centres with $<10$ patients wait listed)

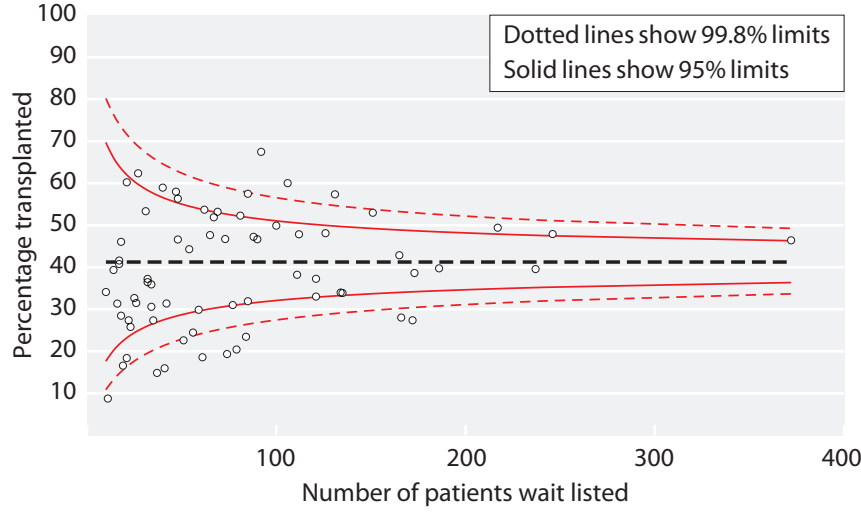

Fig. 11.3. Proportion of patients receiving a transplant from a donor after cardiac death or living donor within 2 yrs of wait listing (excluding centres with $<10$ patients wait listed)

Table 11.5. Proportion of patients receiving a transplant within two years of wait listing, by donor type and renal centre

\begin{tabular}{|c|c|c|c|c|c|c|c|}
\hline \multirow[b]{3}{*}{ Centre } & \multirow{3}{*}{$\begin{array}{l}\text { Wait listed } \\
\qquad N\end{array}$} & \multicolumn{3}{|c|}{ Organ from donor after brainstem death } & \multicolumn{3}{|c|}{$\begin{array}{l}\text { Organ from donor after cardiac } \\
\text { death/living kidney donor }\end{array}$} \\
\hline & & \multirow{2}{*}{$\begin{array}{c}\text { Transplanted } \\
\qquad N\end{array}$} & \multicolumn{2}{|c|}{$\begin{array}{l}\text { Proportion transplanted within } \\
2 \text { years of wait listing (\%) }\end{array}$} & \multirow{2}{*}{$\begin{array}{c}\text { Transplanted } \\
\qquad N\end{array}$} & \multicolumn{2}{|c|}{$\begin{array}{l}\text { Proportion transplanted within } \\
2 \text { years of wait listing (\%) }\end{array}$} \\
\hline & & & Unadjusted & Risk-adjusted & & Unadjusted & Risk-adjusted \\
\hline \multicolumn{3}{|c|}{ Transplanting centre median (IQR) } & - & $13.2(11.7-16.8)$ & - & - & $46.7(37.3-52.3)$ \\
\hline \multicolumn{3}{|c|}{ Non-transplanting centre median (IQR) } & - & $14.8(9.7-18.5)$ & - & - & $34(25.2-47.5)$ \\
\hline \multicolumn{8}{|c|}{ England } \\
\hline B Heart & 84 & 10 & 11.9 & 11.3 & 18 & 21.4 & 23.5 \\
\hline B QEH & 172 & 13 & 7.6 & 8.9 & 47 & 27.3 & 27.4 \\
\hline Basldn & 26 & 1 & 3.8 & 4.3 & 8 & 30.8 & 31.5 \\
\hline Bradfd & 54 & 13 & 24.1 & 24.5 & 21 & 38.9 & 44.3 \\
\hline Brightn & 74 & 11 & 14.9 & 17.0 & 16 & 21.6 & 19.3 \\
\hline Bristol & 134 & 12 & 9.0 & 9.6 & 51 & 38.1 & 34.0 \\
\hline Camb & 92 & 8 & 8.7 & 8.8 & 69 & 75.0 & 67.5 \\
\hline Carlis & 27 & 4 & 14.8 & 14.1 & 19 & 70.4 & 62.4 \\
\hline Carsh & 151 & 13 & 8.6 & 9.3 & 78 & 51.7 & 53.0 \\
\hline Chelms & 40 & 9 & 22.5 & 23.1 & 24 & 60.0 & 58.9 \\
\hline Colchr & 17 & 3 & 17.6 & 14.4 & 8 & 47.1 & 41.6 \\
\hline Covnt & 90 & 10 & 11.1 & 11.7 & 47 & 52.2 & 46.7 \\
\hline Derby & 41 & 7 & 17.1 & 19.6 & 7 & 17.1 & 16.0 \\
\hline Donc & 37 & 6 & 16.2 & 15.2 & 6 & 16.2 & 14.9 \\
\hline Dorset & 51 & 7 & 13.7 & 13.3 & 13 & 25.5 & 22.6 \\
\hline Dudley & 21 & 1 & 4.8 & 4.6 & 4 & 19.0 & 18.4 \\
\hline Exeter & 77 & 14 & 18.2 & 18.8 & 26 & 33.8 & 31.0 \\
\hline Glouc & 34 & 7 & 20.6 & 21.9 & 11 & 32.4 & 30.6 \\
\hline Hull & 65 & 6 & 9.2 & 8.9 & 35 & 53.8 & 47.7 \\
\hline Ipswi & 31 & 5 & 16.1 & 16.1 & 19 & 61.3 & 53.3 \\
\hline$\stackrel{1}{\text { Kent }}$ & 100 & 13 & 13.0 & 11.1 & 52 & 52.0 & 49.9 \\
\hline L Barts & 246 & 28 & 11.4 & 12.3 & 101 & 41.1 & 47.9 \\
\hline L Guys & 131 & 20 & 15.3 & 15.7 & 68 & 51.9 & 57.4 \\
\hline L Kings & 79 & 17 & 21.5 & 25.0 & 14 & 17.7 & 20.4 \\
\hline L Rfree & 217 & 26 & 12.0 & 12.9 & 95 & 43.8 & 49.4 \\
\hline L St.G & 73 & 11 & 15.1 & 15.9 & 31 & 42.5 & 46.7 \\
\hline
\end{tabular}


Table 11.5. Continued

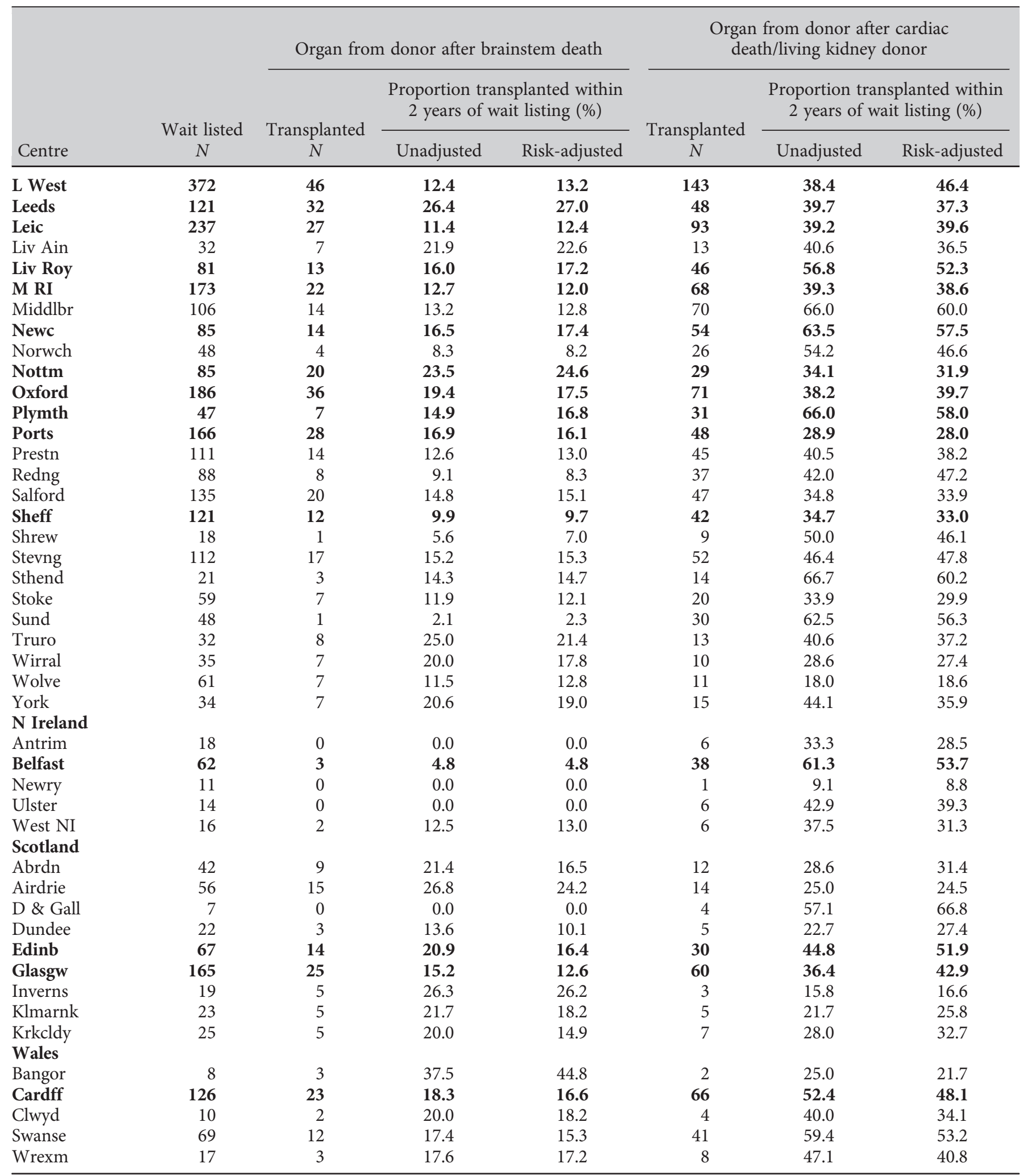

Transplanting renal centres are shown in bold 
Table 11.6. Median time to transplant wait listing by renal centre

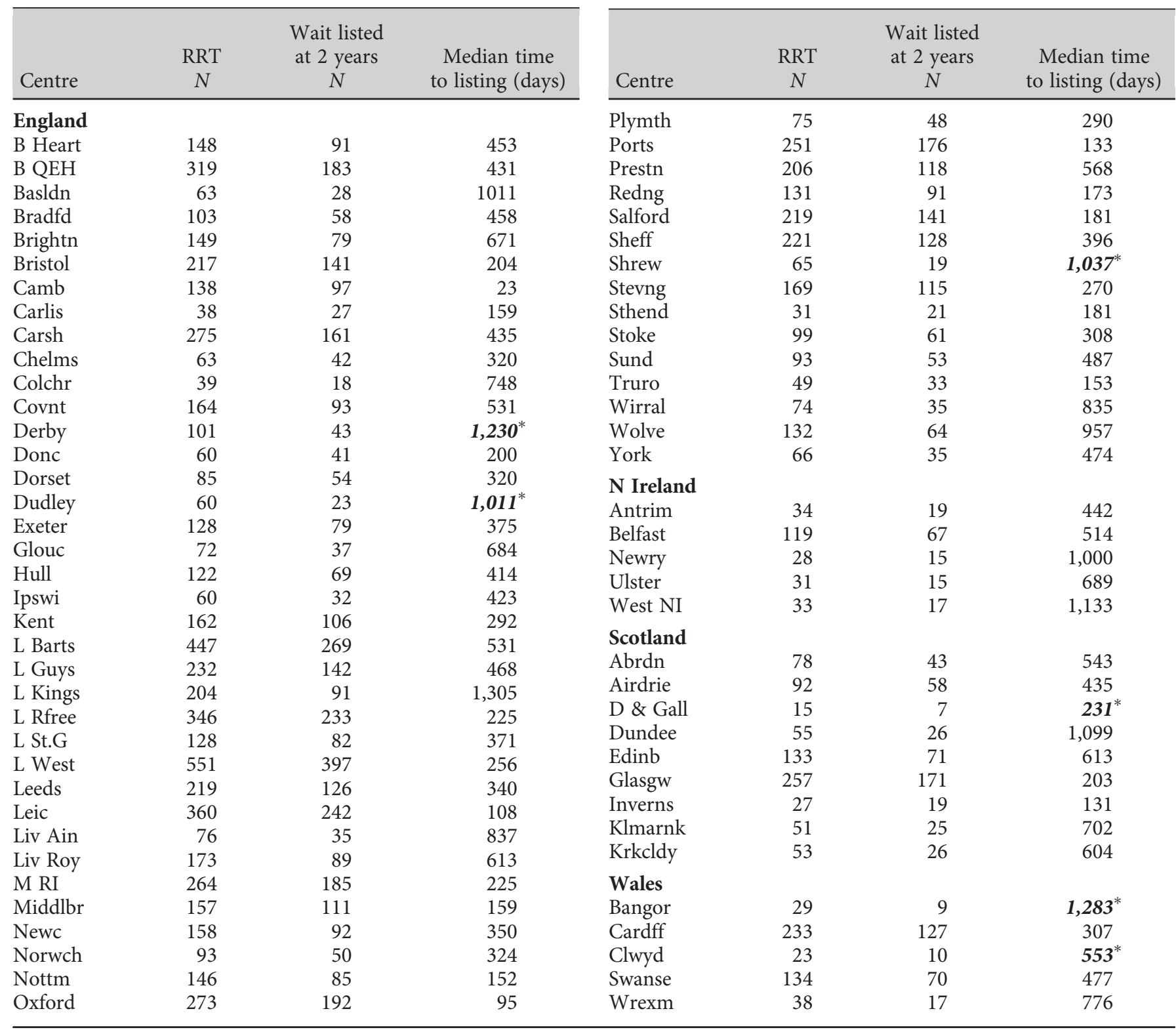

*A result in bold italics is a final event time as median time could not be estimated

\section{Discussion}

Patient characteristics and access to transplantation

Increasing patient age was associated with reduced odds of wait listing and of transplantation from any donor type. This is an expected finding because of the effect of age on the risks and benefits of transplantation: older age is associated with increasing comorbidity and therefore increased clinical risk of transplantation, while the potential benefit of transplantation in extending life reduces with increasing age. Older patients who are suitable for transplantation would be expected to have increased comorbidity and therefore require more screening investigations before being wait listed, reducing the chance of wait listing within two years of RRT start. Reduced odds of receiving a transplant from a donor after brainstem death in older patients reflects the role of age in the national kidney allocation scheme [4].

Patients with a PRD of diabetes were less likely to be wait listed or to receive a transplant from a donor after cardiac death/living donor. The expected increased comorbidity among patients with diabetes may preclude 


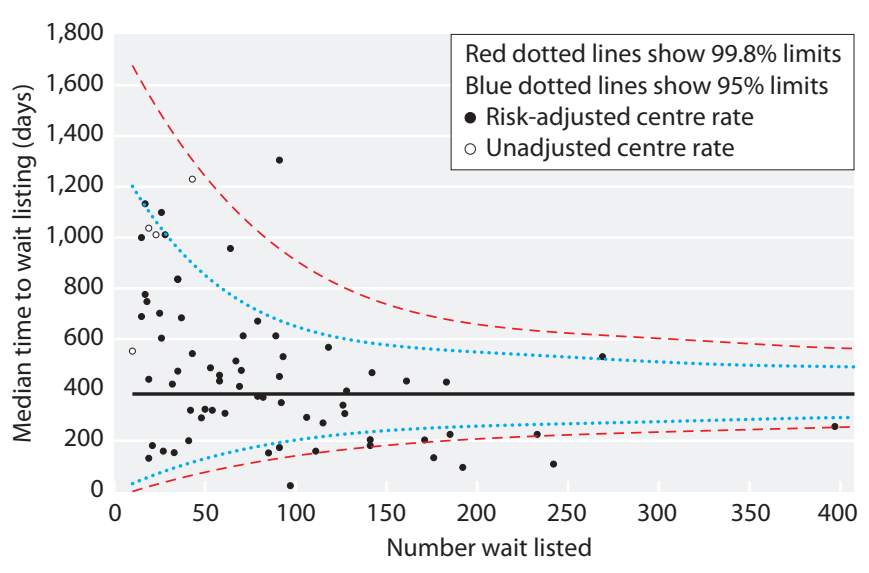

Fig. 11.4. Median time from RRT start to wait listing. Centres represented by an unfilled circle have the final event time as the plotting position as the median time could not be estimated

transplantation or lengthen the medical evaluation process, explaining this finding. Patients with a PRD of diabetes were found to be more likely to receive a transplant from a donor after brainstem death once on the waiting list. This is likely to reflect the prioritisation of dual organ transplantation in organ allocation policy, in addition to the increase in the number of simultaneous kidney pancreas transplants during the study period.

Unlike previous reports, non-White ethnicity did not significantly influence the likelihood of wait listing (OR: 1.03; 95\% CI: $0.93-1.15$, compared with $0.80,0.72-0.89$ in the 2014 Seventeenth Annual Report) [5]. Further, the effect of non-White ethnicity in reducing the chance of transplantation from a donor after brainstem death within two years of listing has diminished compared to data from previous years (OR 0.79; 95\% CI: 0.65-0.95 compared to 0.65 ; $95 \%$ CI: $0.52-0.81$ in analyses from 2008-2010) [5]. The overall effect of these changes is that patients with non-White ethnicity no longer have reduced access to transplantation from donors after brainstem death. This may reflect changes in the practice of transplant wait listing, changes in the demographics of potential transplant recipients with non-White ethnicity, and alterations in the national kidney allocation scheme, which now has less strict criteria in relation to HLA matching. The latter change means that recipients with non-White ethnicity are less likely to be disadvantaged by the relative lack of organs from non-White donors. It should be noted that differences in socioeconomic status between ethnic groups have been found previously to explain differences in access to transplantation by ethnicity $[7,8]$. Lack of adjustment for socioeconomic status therefore limits the reliability of these results.
The UKRR is collaborating with the Access to Transplant and Transplant Outcome Measures (ATTOM) study, whose forthcoming results include analyses with detailed adjustment for comorbidity and individual level socioeconomic status.

When interpreting the analyses in this chapter it is also important to consider the potential impact of missing data on the results. Data are missing either because a renal centre fails to complete relevant fields on their renal IT system or from a failure to extract this data. Missing data may not be at random: patients with increased comorbidity are likely to die sooner, allowing inadequate time for their physician to enter relevant comorbidity data. The very process of working up and listing a patient makes it less likely that data will be missing. It is therefore perhaps not surprising that patients on the national kidney transplant waiting list are more likely to have ethnicity and PRD data reported $(p<0.0001)$.

\section{Centre variation in access to transplantation}

The analyses presented here suggest significant intercentre variation in access to the transplant waiting list and access to transplantation from any donor type, after adjustment for patient demographics and PRD. However, such results should be interpreted with caution. Adjustment for comorbidity included only diabetes as PRD. Other comorbidities, unaccounted for in these analyses, may also preclude or delay wait listing and transplantation. Adjustment for several other factors known to influence access to transplantation, including socioeconomic status, PRD other than diabetes, comorbidity, and HLA sensitisation was not performed. Also, in the analysis of time to transplant wait listing, patients receiving a live donor transplant after starting dialysis but without prior wait listing were recorded as wait listed on the day of transplantation. In reality, such patients are likely to have been adequately prepared for listing before this time.

Whilst the processes of wait listing or transplantation from a donor after cardiac death/living donor are directly influenced by individual centre practice, the allocation of transplants from donors after brainstem death is controlled by the national kidney allocation scheme. Therefore, rates of transplantation from donors after brainstem death should be relatively independent of centre practice differences (except for variation in the acceptance criteria of individual clinicians). As such, the persistence of significant inter-centre variation in rates of transplantation from donors after brainstem 
death is consistent with under-adjustment for patient factors.

After adjustment for patient characteristics, patients treated at transplanting renal centres had increased access to transplant wait listing and to transplantation from a donor after cardiac death or living donor. There was no difference in access to transplants from donors after brainstem death once patients were wait listed. These have been consistent findings in UKRR analyses since 2010, suggesting that reduced contact with clinicians directly involved in transplantation and increased geographical distance to transplanting centres reduces access to transplantation. Of course, this analysis is also subject to concerns about lack of conclusive adjustment for case mix. It also allocates many pre-emptive transplants to transplanting centres, even if the work-up has been initiated in a timely fashion by the non-transplanting

\section{References}

1 Foley RN, Parfrey PS, Sarnak MJ. Clinical epidemiology of cardiovascular disease in chronic renal disease. Am J Kidney Dis 1998; 32(5(suppl 3)):S112-119

2 Wolfe RA, Ashby VB, Milford EL, Ojo AO, Ettenger RE, Agodoa LY, Held PJ, Port FK. Comparison of mortality in all patients on dialysis, patients on dialysis awaiting transplantation, and recipients of a first cadaveric transplant. The New England Journal of Medicine 1999; 341:1725-1730

3 Neipp M, Karavul B, Jackobs S, Meyer zu Vilsendorf A, Richter N, Becker T, Schwarz A, Klempnauer J. Quality of life in adult transplant recipients more than 15 years after kidney transplantation. Transplantation 2006;81(12):1640-1644

4 NHS Blood and Transplant. Policy POL186/7: Kidney Transplantation: Deceased Donor Organ Allocation. http://odt.nhs.uk/pdf/kidney_ allocation_policy.pdf Accessed 2017 centre. Lastly, there is competition between the two outcome variables (transplant from a donor after brainstem death versus transplant from a donor after cardiac death/living donor). As such, patients from centres with a higher rate of transplantation from a donor after cardiac death/living donor may have reduced odds of transplantation from a donor after brainstem death (and vice versa). These issues will be addressed in future analyses, allocating patients according to their location of residence (rather than their treatment centre), and using methodology which accounts for competing risk. In addition, the results of analyses from the ATTOM study with more detailed adjustment for case mix are forthcoming.

Conflicts of interest: the authors declare no conflicts of interest

5 Pruthi R, Curnow E, Roderick P, Ravanan R. UK Renal Registry 17th Annual Report: Chapter 11 Centre Variation in Access to Renal Transplantation in the UK (2008-2010). Nephron 2015;129(suppl 1): 247-256

6 Ravanan R, Udayaraj U, Ansell D, Collett D, Johnson R, O’Neill J, Tomson CR, Dudley CR. Variation between centres in access to renal transplantation in UK: longitudinal cohort study. BMJ 2010;341:c3451

7 Udayaraj U, Ben-Shlomo Y, Roderick P, Casula A, Dudley C, Collett D, Ansell D, Tomson C, Caskey F. Social deprivation, ethnicity, and uptake of living kidney donor transplantation in the United Kingdom. Transplantation 2012;93(6):610-616

8 Udayaraj U, Ben-Shlomo Y, Roderick P, Casula A, Dudley C, Johnson R, Collett D, Ansell D, Tomson C, Caskey F. Social deprivation, ethnicity, and access to the deceased donor kidney transplant waiting list in England and Wales. Transplantation 2010;90(3):279-285 